\title{
Low-Voltage Ride-Through Capability of a Single-Stage Single-Phase Photovoltaic System Connected to the Low-Voltage Grid
}

\author{
Yongheng Yang and Frede Blaabjerg \\ Department of Energy Technology, Aalborg University, Pontoppidanstraede 101, 9220 Aalborg, Denmark \\ Correspondence should be addressed to Yongheng Yang; yoy@et.aau.dk
}

Received 11 September 2012; Accepted 17 December 2012

Academic Editor: Sih-Li Chen

Copyright (C) 2013 Y. Yang and F. Blaabjerg. This is an open access article distributed under the Creative Commons Attribution License, which permits unrestricted use, distribution, and reproduction in any medium, provided the original work is properly cited.

\begin{abstract}
The progressive growing of single-phase photovoltaic (PV) systems makes the Distribution System Operators (DSOs) update or revise the existing grid codes in order to guarantee the availability, quality, and reliability of the electrical system. It is expected that the future PV systems connected to the low-voltage grid will be more active with functionalities of low-voltage ride-through (LVRT) and the grid support capability, which is not the case today. In this paper, the operation principle is demonstrated for a single-phase grid-connected PV system in a low-voltage ride-through operation in order to map future challenges. The system is verified by simulations and experiments. Test results show that the proposed power control method is effective and the single-phase PV inverters connected to low-voltage networks are ready to provide grid support and ride-through voltage fault capability with a satisfactory performance based on the grid requirements for three-phase renewable energy systems.
\end{abstract}

\section{Introduction}

More and more single-phase photovoltaic (PV) systems are connected to the public grid mainly because of the matured PV technology and the declined price of the PV module cell [1]. As it is reported by PHOTON International, there was $27.7 \mathrm{GW}$ of global PV generation systems installed in 2011, nearly $21 \mathrm{GW}$ in Europe, which makes accumulated installed global PV capacity be around $70 \mathrm{GW}$ at the end of 2011. It can be foreseen that the future grid-connected PV systems will play a very important role in the regulation of the conventional power systems.

However, behind the thriving penetration of singlephase grid-connected PV systems, the phenomenon of largescale Distributed Generation (DG) systems connected to the public grid also raises some concern on the availability, quality, and reliability of the grid. On this basis, many grid requirements are published in recent years by the Transmission System Operators, Distribution System Operators, or international standard committees (e.g., IEC and IEEE) in order to regulate the interaction between DGs and the public grid [2-9]. In spite of this fact, most of these grid requirements are focused on three-phase wind power systems or DGs connected to medium- or high-level grid. There are few grid codes and papers describing the demands for PV systems connected to low-level grid, like single-phase PV systems $[6,10-15]$.

Due to the fast growing installations of grid-connected PV systems, it is expected that the future PV systems will be more active and "smart" with the functionalities of lowvoltage ride-through capability and grid support, which are required for three-phase wind power systems. In the future, the grid-connected PV system needs to fulfill the basic grid requirements, like power quality demand, and also provides some ancillary services likewhat the conventional power plant does. For instance, the PV inverters should inject some reactive current when the grid presents a voltage sag fault. In that case, the control strategies should be developed in order to help the PV system ride-through during the grid faults.

For single-phase applications, the calculation of active and reactive power is a big challenge, which leads to the 
difficulty of direct instantaneous power control. Unlike threephase systems, it is difficult to employ directly a $d q$-rotating synchronous reference frame in single-phase systems to implement positive sequence control or constant reactive power control $[7,8,16]$. Possible solutions for single-phase applications are based on the single-phase $P Q$ theory, instantaneous power control, or the droop control concept [13, 1720]. Moreover, the grid fault detection and synchronization techniques are also challenges for the single-phase system when operating in the grid fault mode.

In this paper, the overall control strategy for single-phase PV systems in the grid faulty mode operation is demonstrated based on the grid requirements defined for three-phase wind power systems as it is expected that they will be the basic requirements for single-phase $\mathrm{PV}$ systems. A transport delay grid fault detection method is adopted in this study. A power control method based on the single-phase $P Q$ theory and the Proportional-Resonant (PR) current control scheme is proposed. Finally, the system is tested in simulation and verified by experiments. The results show that the singlephase PV systems are ready for providing ancillary service in the future and the grid detection method has a significant impact on the performance of the single-phase PV systems under grid faults.

\section{Grid Requirements}

The grid requirements for DGs are updated and revised based on the development and penetration level of DGs and issued in the form of national grid code [2-6], such as E.ON grid code and CEI grid code published by Comitato Elettrotecnico Italiano. In these grid codes, the basic demands are imposed like the power quality (the THD level of the injected current) and the anti-islanding requirement. Considering the penetration level of DGs connected to the grid, combined requirements are expected to be added into the grid codes in the future.

For example, in the German grid code, the DGs should handle ride-through grid fault, known as low-voltage ridethrough (LVRT) capability, and support the grid during the voltage recovery. Similar requirements can be found in other countries, like Denmark, Italy, Spain, and USA in which the DGs share a high percentage of power generation. The LVRT capability is defined so that the DG should stay connected to the grid within a short time and inject some reactive power to support the grid when the grid presents a voltage fault. Different LVRT curves with defined stay-connected time are shown in Figure 1.

As it is shown in Figure 1, the DGs should stay connected to the grid when the voltage drops to $0 \mathrm{~V}$ in the German grid code in 0.15 seconds. At the same time, the system should inject some reactive current in order to support the grid recovery according to Figure 2.

These grid requirements are set to ensure the safety of utility maintenance personnel and also other devices connectedto the public grid and to avoid the grid collapse due to voltage faults. It is expected that these grid requirements will be recommended to be used to regulate single-phase

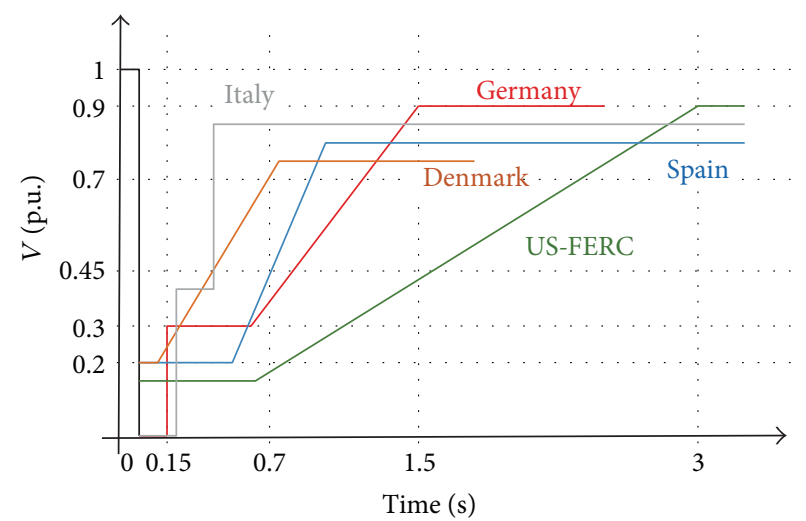

FIGURE 1: Low-voltage ride-through (LVRT) requirements of Distributed Generation systems in different countries $[2,5]$.

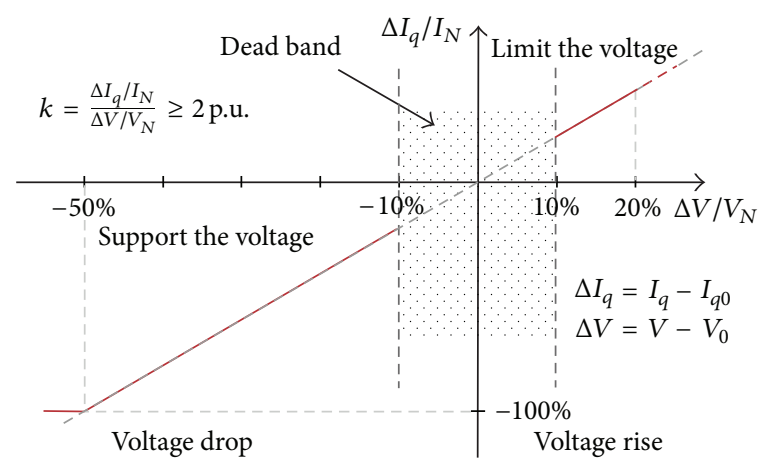

FIGURE 2: Voltage support requirement under grid faults for wind turbines [3].

PV systems, since the impact of large-scale single-phase PV systems on the low-level public grid cannot be ignored. The discussion in this paper is based on these requirements.

\section{Single-Phase Grid-Connected Photovoltaic System in the Grid Faulty Mode Operation}

3.1. System Configuration. In consideration of the whole conversion efficiency, a single-stage PV system is connected to the grid through a transformer, which is shown in Figure 3. In some cases, a voltage-boost stage can be used between the DC capacitor $C$ and the inverter, depending on the output voltage level of the PV panels. The boost stage makes the system flexible track the Maximum Power Point (MPP) of the PV panel and also makes it possible to handle the power variation across the DC capacitor $C$ at twice the grid fundamental frequency [9].

The control system shown in Figure 3 consists of a voltage sag detection unit, an Orthogonal Signal Generator (OSG) for power calculation, the power profiles including MPPT control in normal operation, active and reactive power controllers for current reference generation, a grid current controller, and a PWM generation block.

As it can also be seen in Figure 3, in order to implement grid fault operation mode for this system, a voltage sag 


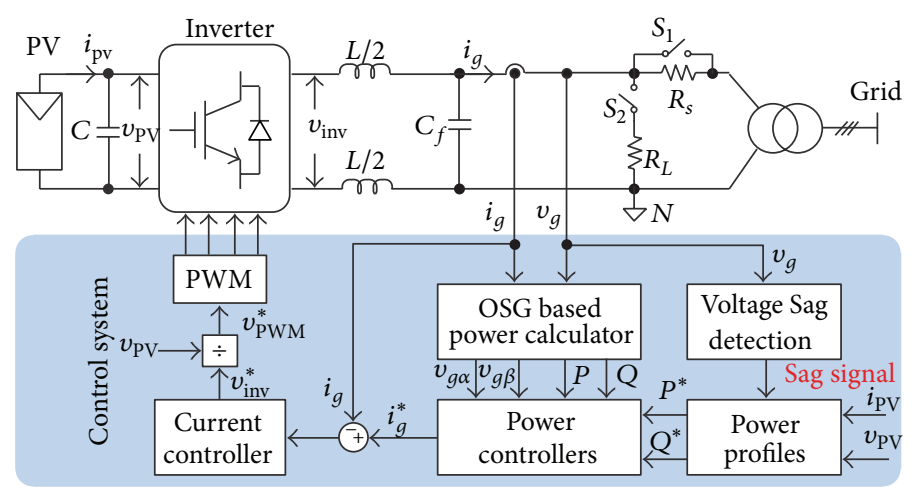

FIGURE 3: Overall structure of a single-phase grid-connected PV system, OSG: Orthogonal Signal Generator.

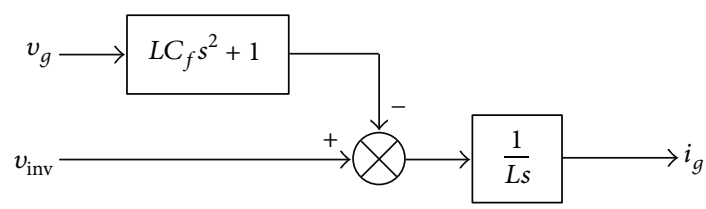

FIGURE 4: Equivalent model of the output LC filter in the Laplace domain.

generator is used by switching the series resistor $R_{s}$ and the load resistance $R_{L}$. During the LVRT mode operation, the switch $S_{1}$ is open in order to limit the short-circuit effect on the upstream grid and the switch $S_{2}$ is closed, while in normal operation, $S_{1}$ is closed and $S_{2}$ is open.

An $L C$ filter $\left(L C_{f}\right)$ is used as the output filter in order to limit the high-order harmonics coming from the inverter switching behavior. Thus, neglecting all the filter losses, the system at the AC side can be described by

$$
\frac{d i_{g}(t)}{d t}=\frac{v_{\text {inv }}(t)}{L}-C_{f} \frac{d^{2} v_{g}(t)}{d t^{2}}-\frac{v_{g}(t)}{L},
$$

in the time domain and

$$
I_{g}(s)=\frac{1}{L s} V_{\mathrm{inv}}(s)-\left(C_{f} s^{2}+\frac{1}{L s}\right) V_{g}(s),
$$

in the Laplace domain, where $i_{g}$ is the injected grid current, $v_{\text {inv }}$ is the inverter output voltage, and $v_{g}$ is the grid voltage. Hence, the equivalent model of the output filter can be given as it is shown in Figure 4.

3.2. Voltage Sag Detection. Grid condition information is very important for the control system to perform special functionalities. Similarly, as a part of the grid condition detection, the voltage sag detection is the way to identify the voltage fault and it determines the dynamic performance of the voltage sag compensator $[21,22]$ and the behavior of the whole control system. It is easy to understand that the system should switch from normal operation mode to grid fault operation mode as soon as possible, once the voltage sag is detected. Hence, it is essential to have a precise and fast fault detection unit.

Recently, many voltage sag detection methods have been proposed, such as Root Mean Square (RMS) method, peak value method (OSG based sag detection techniques), the missing voltage technique, and wavelet transform method [10, 21-25]. The RMS method computes the RMS value of the input signal by using a running average window of one cycle. Therefore, theoretically, this method will introduce one cycle delay in order to give the correct value. The wavelet transform based voltage sag detection is becoming of high interest [24], because of its fast detection speed. However, the implementation of this method is unfortunately not easy in real time.

In this paper, the peak value method is used to detect the voltage fault. The implementation of this method is easy, and by means of the OSG system, it is possible and flexible to calculate the average active and reactive power instantaneously. Since the T/4 Delay structure is used to build up the OSG system as it is shown in Figure 5, the system will introduce a quarter period time delay of the input fundamental period. The peak value of the input voltage can be given by

$$
V_{m}=\sqrt{v_{g}^{2}+v_{g}^{\prime 2}}=\sqrt{V_{m}^{2} \sin ^{2}(\omega t)+V_{m}^{2} \cos ^{2}(\omega t)}
$$

where $v_{g}^{\prime}$ is the orthogonal signal of the input voltage generated by shifting a quarter period of the input signal.

3.3. Power Calculation and Power Profiles. In different operation modes, the power profiles are different. Firstly, the average active power $P$ and reactive power $Q$ of the system are computed using Discrete Fourier Transform (DFT) structure, as it is shown in Figure 6.

Under normal grid conditions, the system is operating in Maximum Power Point Tracking (MPPT) mode in order to deliver as much energy as possible to the grid, and the power factor is normally near to one. According to the grid requirements, in grid faulty mode operation, the single-phase PV inverter should inject some reactive power into the grid to support the grid voltage during recovery. The amount of 


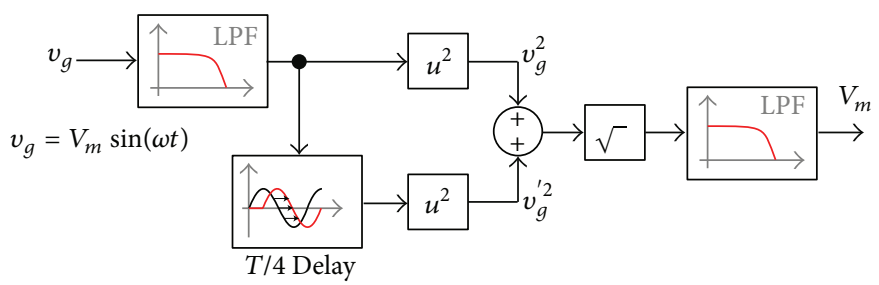

FIGURE 5: Voltage sag detection by monitoring the peak value based on T/4 Delay orthogonal system.

reactive power should be injected dependent on the voltage sag depth and the inverter rating current. At the same time, the PV panels should switch to non-MPPT operation mode in order to avoid tripping the inverter overcurrent protection $[10,26,27]$. The operation modes are described in Figure 7.

By employing Park transform $(\alpha \beta \rightarrow d q)$ to the grid voltage and current in the OSG systems, the active power $P$ and reactive power $Q$ delivered to the grid can also be calculated and expressed as

$$
\begin{gathered}
P=\frac{1}{2} v_{g d} i_{g d}, \\
Q=-\frac{1}{2} v_{g d} i_{g q},
\end{gathered}
$$

where the subscripts " $g d$ " and " $g q$ " denote the " $d$ " and " $q$ " components of the grid voltage/current in a $d q$-rotating synchronous reference frame.

As it is stated above, in normal MPPT operation mode, the system is operating at unity power factor. Then, neglecting the switching power losses, the active power $P$ and reactive power $Q$ can be obtained:

$$
\begin{gathered}
P=\frac{1}{2} V_{m} i_{g d}=\frac{1}{2} V_{m} I_{m} \approx P_{\mathrm{PV}, \mathrm{MPP}}, \\
Q=-\frac{1}{2} V_{m} i_{g q}=0,
\end{gathered}
$$

in which $V_{m}$ and $I_{m}$ are the amplitude of the grid voltage and current in MPPT operation mode, respectively, $P_{\mathrm{PV}, \mathrm{MPP}}$ is the tracked maximum output power of the PV panels.

In faulty grid operation mode, according to Figure 2, the required reactive current under voltage sags can be given as

$$
I_{q}= \begin{cases}\begin{array}{l}
\text { deadband, } \\
k \cdot \frac{V-V_{0}}{V_{N}} \cdot I_{N}+I_{q 0},
\end{array} & 0.9 \text { p.u. } \leq V \text { p.u. } \leq V<0.9 \text { p.u. } \\
-I_{N}+I_{q 0}, & V<0.5 \text { p.u. }\end{cases}
$$

in which $V, V_{0}$, and $V_{N}$ are the amplitude values of the grid instantaneous voltage, initial voltage before grid faults, and the nominal grid voltage, $I_{N}, I_{q 0}$ are the nominal current and the initial reactive current before a grid failure, and $k=$ $\left(\Delta I_{q} / I_{n}\right) /\left(\Delta V / V_{n}\right) \geq 2$ p.u.. By substituting (6) into (4), the

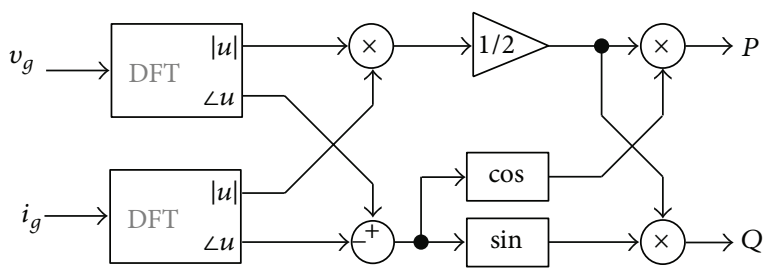

FIgURE 6: Power calculation based on Discrete Fourier Transform (DFT).

required active power $P^{*}$ and reactive power $Q^{*}$ reference in the grid faulty mode operation can be given as

$$
\begin{gathered}
P^{*}=\frac{1}{2} V I_{d} \approx P_{\mathrm{PV}}, \quad \sqrt{I_{d}^{2}+I_{q}^{2}}=I_{N} \\
Q^{*}=\frac{1}{2} V I_{q},
\end{gathered}
$$

where $P_{\mathrm{PV}}$ is the output power of the PV panel in the grid faulty mode operation.

Normally, the nominal current is limited by the inverter maximum rating current, $I_{N} \leq I_{\max }$, where $I_{\max }$ is the inverter maximum rating current and the initial reactive current is zero, $I_{q 0}=0 \mathrm{~A}$.

According to (7) and Figure 7, the PV panels should "derate" its output power when the grid presents a voltage fault, as it can be illustrated in Figure 8 . The derated power level $\left(P_{\mathrm{PV}, \mathrm{MPP}} \rightarrow P^{*}\right.$ or $\left.P_{\mathrm{PV}}\right)$ is dependent on the voltage sag depth and the nominal current. If the voltage drop is small, either by decreasing the PV voltage reference or increasing it can limit the PV output power. However, it should be noted that the PV voltage must be in the inverter input voltage range.

\subsection{Power Controllers and Current Reference Generation.} Similar to the power calculation in the $d q$-rotating reference frame, the active power $P$ and reactive power $Q$ for a singlephase application can be computed with the help of OSG systems:

$$
\begin{aligned}
& P=\frac{1}{2}\left(v_{g \alpha} i_{g \alpha}+v_{g \beta} i_{g \beta}\right), \\
& Q=\frac{1}{2}\left(v_{g \beta} i_{g \alpha}-v_{g \alpha} i_{g \beta}\right),
\end{aligned}
$$




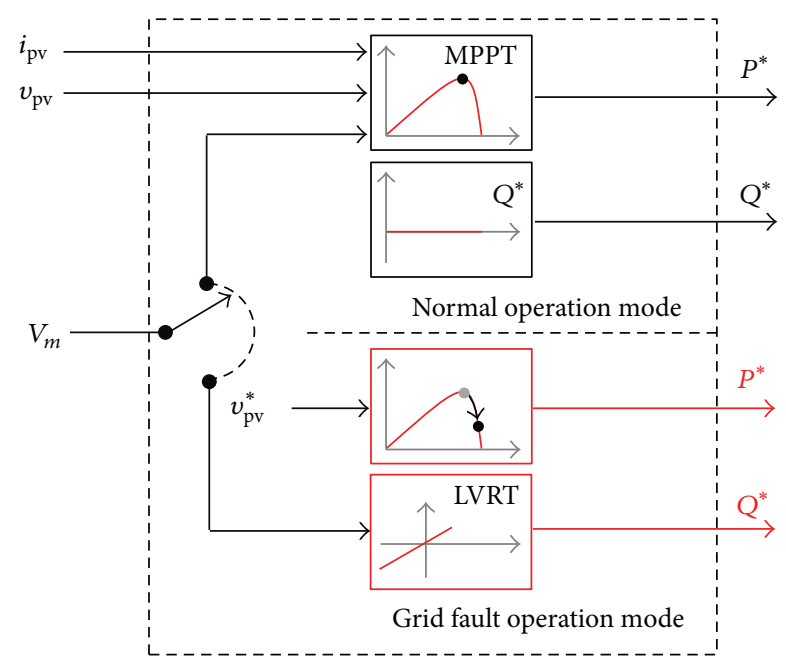

Figure 7: Power profiles for a single-phase grid-connected PV system in different operation modes.

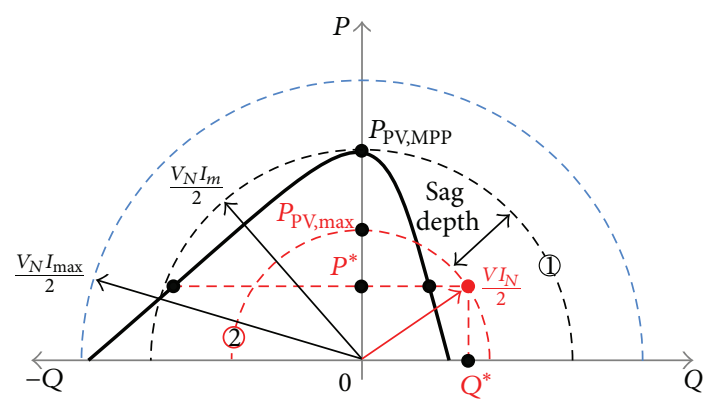

FIGURE 8: PQ diagram and PV power-voltage curve (black bold line) in different operation modes: (1) MPPT mode and (2) grid fault mode.

in which the subscripts " $g \alpha$ " and " $g \beta$ " denote the " $\alpha$ " and " $\beta$ " components of the grid voltage/current in a $\alpha \beta$-stationary reference frame.

In this way, the currents in a $\alpha \beta$-stationary reference frame can be expressed as

$$
\left[\begin{array}{l}
i_{g \alpha} \\
i_{g \beta}
\end{array}\right]=\frac{2}{v_{g \alpha}^{2}+v_{g \beta}^{2}}\left[\begin{array}{cc}
v_{g \alpha} & v_{g \beta} \\
v_{g \beta} & -v_{g \alpha}
\end{array}\right]\left[\begin{array}{l}
P \\
Q
\end{array}\right] .
$$

Since the active power and reactive power are DC quantities in steady state, it is possible to use PI controllers for power regulation, and thus the current reference can be given by

$$
\left[\begin{array}{l}
i_{g \alpha}^{*} \\
i_{g \beta}^{*}
\end{array}\right]=\frac{1}{v_{g \alpha}^{2}+v_{g \beta}^{2}}\left[\begin{array}{cc}
v_{g \alpha} & v_{g \beta} \\
v_{g \beta} & -v_{g \alpha}
\end{array}\right]\left[\begin{array}{c}
G_{p}(s)\left(P-P^{*}\right) \\
G_{q}(s)\left(Q-Q^{*}\right)
\end{array}\right]
$$

where “*” denotes the reference signal, $G_{p}(s)$ and $G_{q}(s)$ are the transfer functions of the PI controllers for active power and reactive power, respectively, and which can be given by

$$
\begin{aligned}
& G_{p}(s)=K_{p p}+K_{p i} \frac{1}{s}, \\
& G_{q}(s)=K_{q p}+K_{q i} \frac{1}{s} .
\end{aligned}
$$

3.5. Current Controller with Harmonic Compensation. The existing current control methods, such as Proportional Resonant (PR) [28, 29], Deadbeat control (DB), Repetitive controller (RC) [30], and PI control which needs a Park transform $(\alpha \beta \rightarrow d q)$ [29], can be adopted in different operation modes. In this case, the PR controller is used. For the purpose of the suppression of the injected current harmonics, resonant harmonic compensation method is employed, which is shown in Figure 9.

Hence, the current closed-loop transfer function $\left(i_{g}(s) / i_{g}^{*}(s)\right)$ can be expressed as

$$
\frac{i_{g}(s)}{i_{g}^{*}(s)}=\frac{G_{\mathrm{PR}+\mathrm{HC}}(s) \cdot G_{d}(s)}{L s+G_{\mathrm{PR}+\mathrm{HC}}(s) \cdot G_{d}(s)},
$$

in which $G_{\mathrm{PR}+\mathrm{HC}}(s)$ is the transfer function of PR controller with harmonics compensation and $G_{d}(s)$ is the processing and PWM delay [28]. $G_{\mathrm{PR}+\mathrm{HC}}(s)$ and $G_{d}(s)$ have the following expressions:

$$
\begin{gathered}
G_{\mathrm{PR}+\mathrm{HC}}(s)=k_{p}+\frac{k_{i} s}{s^{2}+\omega_{0}^{2}}+\sum_{h=3,5,7, \ldots} \frac{k_{i h} s}{s^{2}+\left(h \omega_{0}\right)^{2}}, \\
G_{d}(s)=\frac{1}{1+1.5 T_{s} s},
\end{gathered}
$$

where $k_{p}$ is the proportional gain, $k_{i}$ and $k_{i h}$ are the resonant and harmonic compensator gains, $h$ is the harmonic order, $\omega_{0}$ is the fundamental frequency, and $T_{s}$ is the sampling period.

Hereafter, according to the above illustration, the whole control diagram can be structured, as it is shown in Figure 10. It can be seen from Figures 9 and 10 that the harmonics in the grid voltage $v_{g}$ will propagate to the grid current reference $i_{g}^{*}$. However, the cascaded harmonic compensators will suppress the harmonics if the gains around the resonance frequencies are high enough. The Bode diagram of the PR controller with selective harmonics compensation is shown in Figure 11, which can be used to tune the parameters, $k_{p}, k_{i}$, and $k_{i h}$. It is shown in Figure 11 that the selection of a large $k_{i h}$ leads to a wide frequency band around the resonance point [8].

It is also worth to point out that the voltage variation of the DC capacitor (DC-link voltage) at twice the grid fundamental frequency will introduce even harmonics in the injected current. Moreover, in faulty grid operation mode, this distortion is much more severe. In this case, the harmonic compensation method by cascading several resonant controllers will cause heavy computation burden and become less practical, when the higher order harmonics need to be compensated [30]. 


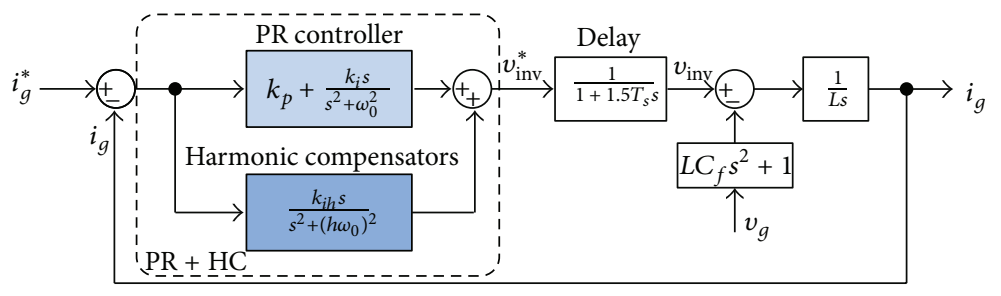

FIGURE 9: Current control loop with PR controller and harmonic compensation to eliminate harmonic voltage distortion.

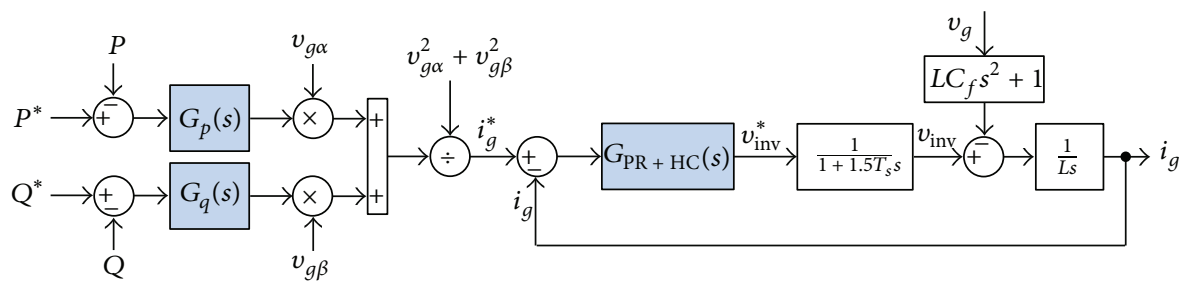

FIGURE 10: Control diagram of a single-phase grid-connected system with PR controller and harmonic compensators based on single-phase $P Q$ theory.

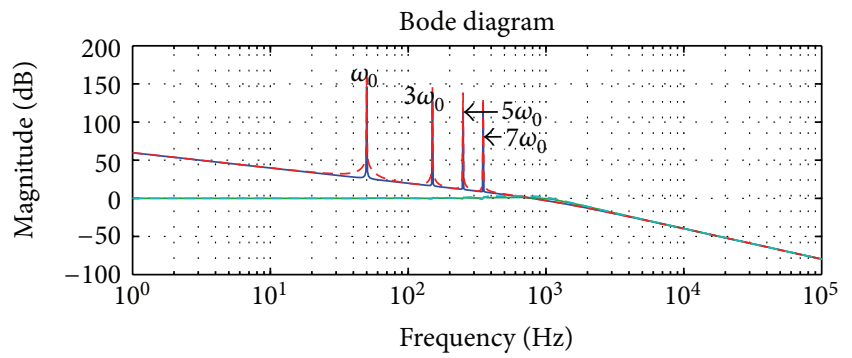

(a)

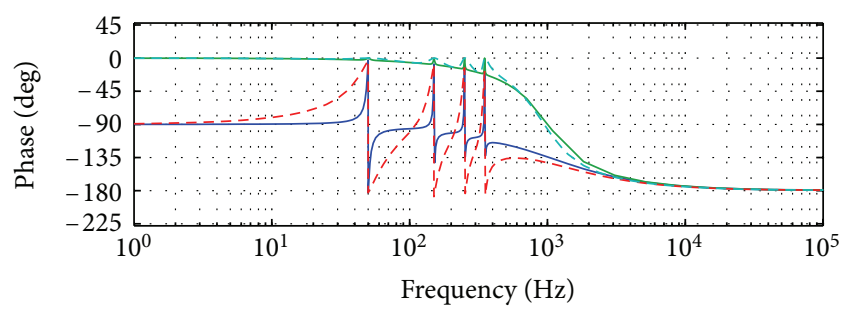

(b)

FIGURE 11: Open-loop (blue) and closed-loop (black) Bode diagrams of the current controller with different sets of $k_{i h}: k_{p}=22, k_{i h}=500$ (solid line), and $k_{i h}=5000$ (dashed line), where $h=1,3,5,7$.

\section{Simulation and Experimental Results}

Referring to Figures 3 and 10, the whole system is simulated in MATLAB in order to verify the performance of the proposed power control method. In this system, the PV panel is modeled by means of a 3D look-up table [31]. The nominal maximum power $P_{\mathrm{PV}, \mathrm{MPP}}$ is $1030 \mathrm{~W}$, the voltage $V_{\mathrm{PV}, \mathrm{MPP}}$ and current $I_{\mathrm{PV}, \mathrm{MPP}}$ at the maximum power point are $400 \mathrm{~V}$ and $2.56 \mathrm{~A}$, respectively. The Incremental Conductance
TABLE 1: Simulation and experimental parameters.

\begin{tabular}{lc}
\hline Grid voltage amplitude & $V_{N}=325 \mathrm{~V}$ \\
Grid frequency & $\omega_{0}=2 \pi \times 50 \mathrm{rad} / \mathrm{s}$ \\
$L C$ filter & $L=3.6 \mathrm{mH}, C_{f}=2.35 \mu \mathrm{F}$ \\
Transformer leakage inductance and & $L_{g}=4 \mathrm{mH}, R_{g}=0.02 \Omega$ \\
resistance & $f_{s}=f_{s w}=10 \mathrm{kHz}$ \\
Sampling and switching frequency
\end{tabular}

(INC) MPPT method is adopted to capture the maximum output power of the PV system. This INC method is modified according to Figures 7 and 8 in order to limit the output power when the grid voltage drops, presenting a grid fault. The other simulation parameters are listed in Table 1 . The PI controller parameters for this simulation are $k_{p p}=6.2, k_{p i}=1.5, k_{q p}=$ 1 , and $k_{q i}=50$. Simulation results are provided in Figures 12 and 13.

As it is shown in Figures 12 and 13, the single-stage single-phase PV system is subjected to a grid fault (about 0.35 p.u.) at $t=0.7 \mathrm{~s}$. This voltage sag lasts for about $320 \mathrm{~ms}$. Since the detection unit needs a few milliseconds $(\Delta t)$ to give the correct operation condition of the grid, instead of an immediate response, the MPPT and the control units continue to operate as in a normal condition and thus the grid current rises in this time interval. It happens similarly after the fault is cleared.

Once the grid fault is detected, the MPPT unit is disabled and the control system is switched to grid fault operation mode as it is shown in Figure 7. Soon after, the system starts to inject reactive current as required and limit the active power output to prevent the inverter from overcurrent protection. After the fault is cleared (voltage rises to 0.9 p.u.), the system goes back to its normal operation, and again, it is trying to 


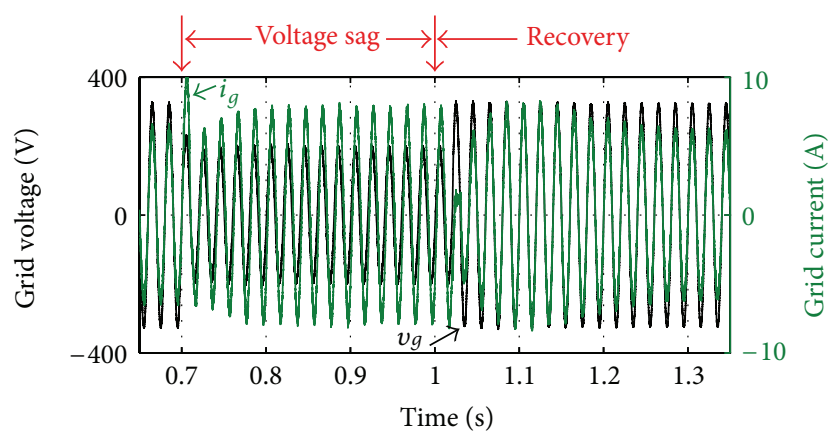

(a)

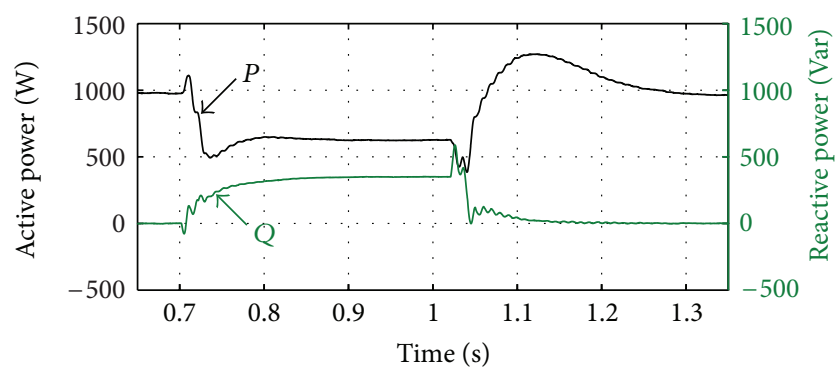

(b)

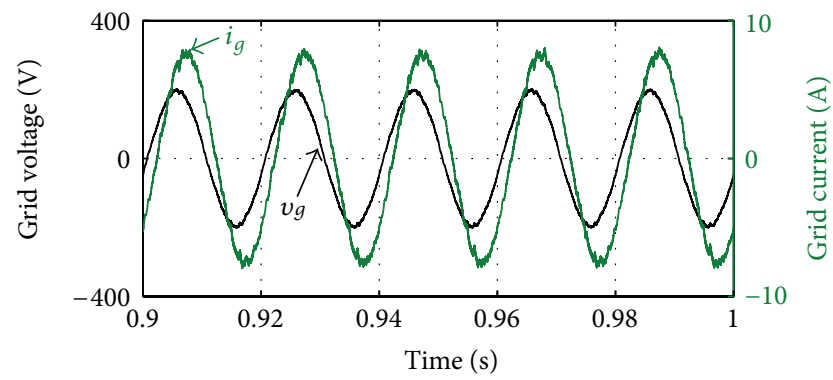

(c)

FIGURE 12: Simulation results for a single-phase PV system under grid fault: (a) grid voltage and current; (b) active and reactive power; (c) grid voltage and current during LVRT.

track the maximum output power of the PV panels. However, as it is shown in Figures 12 and 13, it may take some time because of the MPPT perturbing process.

In order to validate the effectiveness of the proposed control method, the system is also tested experimentally. Instead of some real PV panels, two DC sources are used as the input power. The whole system consists mainly of

(i) two Delta Elektronika SM 300-5 DC power supply, the nominal DC voltage, $V_{\mathrm{DC}}=400 \mathrm{~V}$,

(ii) two DC capacitors connected in parallel, the equivalent capacitance, $C=1100 \mu \mathrm{F}$,

(iii) a Danfoss VLT FC302 3-phase inverter which is configured as a single-phase inverter,

(iv) a sag generator as shown in Figure $3, R_{s}=19.2 \Omega$ and $R_{L}=20 \Omega$,

(v) a $5 \mathrm{kVA} 3$-phase transformer with leakage inductance $L_{g}=2 \mathrm{mH}$ and resistance $R_{g}=0.01 \Omega$ per phase,

(vi) a DS 1103 dSPACE control system.

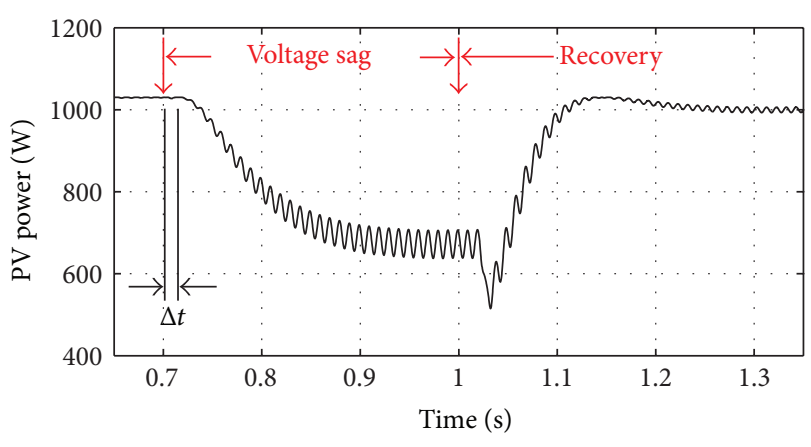

(a)

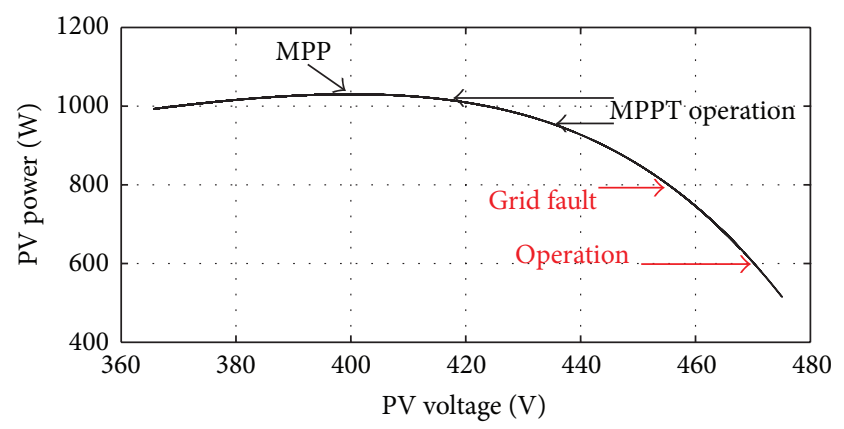

(b)

Figure 13: Simulation results for a single-phase PV system under grid fault: (a) PV panel output power; (b) PV panel output power versus its voltage.

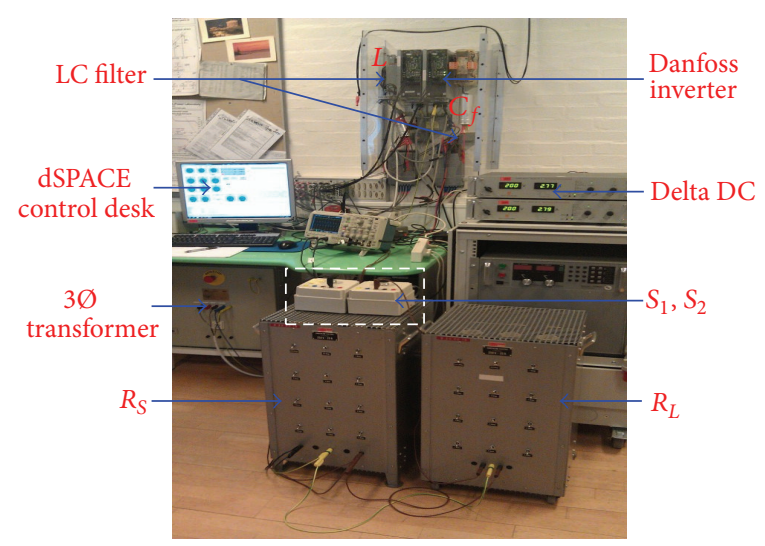

FIGURE 14: Experimental setup of a single-phase grid-connected system.

The PI controller parameters for active power regulation are $k_{p p}=1.2$ and $k_{p i}=50$, while the parameters for reactive power control are $k_{q p}=1$ and $k_{q i}=50$. The other parameters of the single-phase system are shown in Table 1. A voltage drop is generated by switching the manual switches $S_{1}$ and $S_{2}$, which are shown in Figure 14. The experimental results are given in Figure 15.

As it is shown in the experimental results, when the grid is subjected to a voltage sag ( 0.45 p.u.), the detection and control units of the single-phase system cannot react to this sudden change immediately, and thus the grid current is 


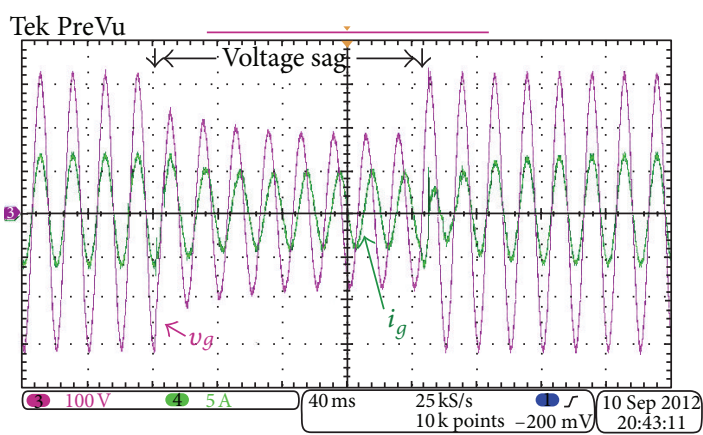

(a)

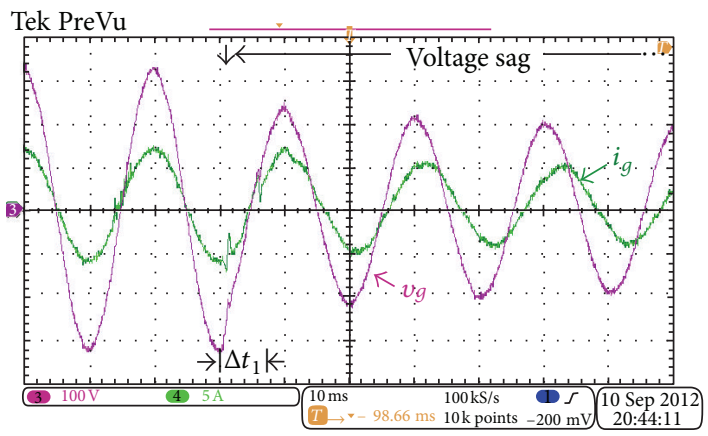

(c)

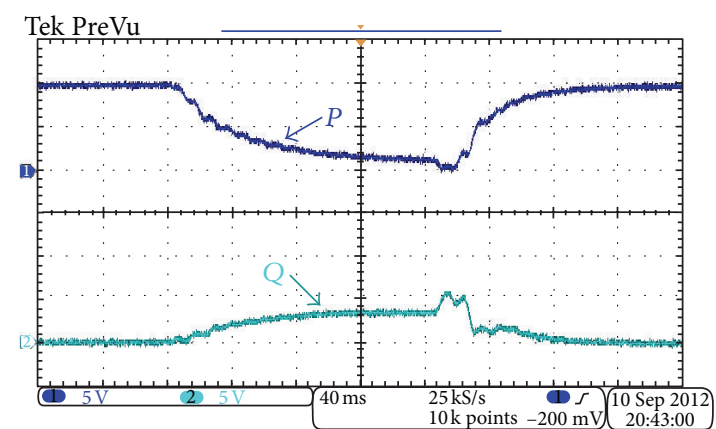

(b)

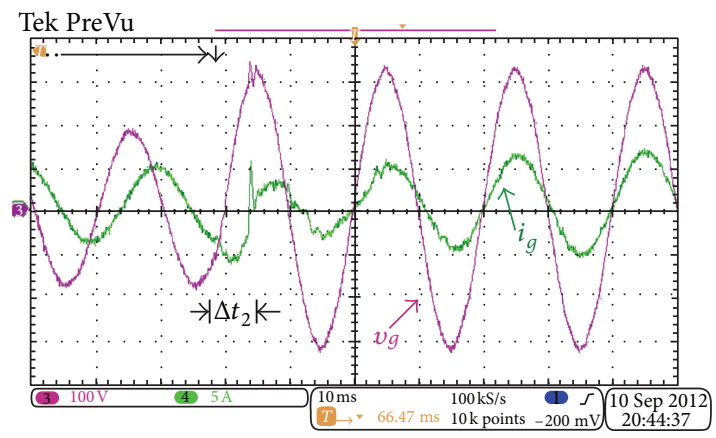

(d)

FIGURE 15: Experimental results of a single-phase system under grid fault based on the single-phase $P Q$ theory and $T / 4$ Delay sag detection method: (a) grid voltage $v_{g}: 100 \mathrm{~V} / \mathrm{div}$ and grid current $i_{g}: 5 \mathrm{~A} / \mathrm{div}$; (b) active power $P: 500 \mathrm{~W} / \mathrm{div}$ and reactive power $Q$ : $500 \mathrm{Var} / \mathrm{div}$; (c) dynamic performance of grid voltage and current at the start of sag; (d) dynamic performance of grid voltage and current at the end of sag.

going to enter into a zone where the current reference is not appropriate until the detection unit outputs the sag signal. During the LVRT operation mode, the system is injecting some reactive power into the power grid and at the same time the active power is limited in consideration of the current limitation of the PV inverter, which is shown in Figure 15(b). When the voltage sag is cleared (the voltage amplitude goes to $90 \%$ of the nominal value), the system returns to its normal operation mode and is injecting current at unity power factor.

It is also shown in Figure 15 that both the start of the voltage sag and the end of that present a transient time delay $\left(\Delta t_{1}\right.$ and $\left.\Delta t_{2}\right)$ which is approximately $5 \mathrm{~ms}(T / 4)$. Firstly, it is because of the fault detection time delay (T/4 Delay sag detection method) as illustrated in the previous paragraph. The power profile might be another reason since it is a step change when the voltage goes back to $90 \%$ of the nominal value. The response of the current controller may deteriorate the dynamics as well. Therefore, fast and accurate grid detection and reasonable power profile are necessary for a single-phase system in the grid fault mode operation.

However, the simulation and experimental results demonstrate the flexibility of a single-phase system to provide grid support functionality. The power control method in the test is effective to do so and it can do it fast.

\section{Conclusion}

Based on the existing grid requirements, this paper discussed the potential of a single-stage single-phase system operating in grid fault condition. The power control method proposed in this paper is effective when the system is switched to grid fault operation mode. It can be concluded that the future single-phase grid-connected PV systems are ready to be more active and more "smart" in the regulation of power grid. Like the conventional generation systems, the single-phase PV systems can also offer some ancillary service in the presence of an abnormal grid condition. However, the performance is dependent on the grid detection and control methods.

\section{Acknowledgment}

The authors would like to thank China Scholarship Council (CSC) for supporting this Ph.D. project in the Department of Energy Technology at Aalborg University, Denmark.

\section{References}

[1] EPIA, "EPIA-Photovoltaic Market Report, 2011," http://www .epia.org/. 
[2] F. Iov, A. D. Hansen, P. E. Sørensen, and N. A. Cutululis, "Mapping of grid faults and grid codes," Tech. Rep., Risø National Laboratory, Technical University of Denmark, 2007.

[3] E. ON GmbH, "Grid Code-High and extra high voltage," http://www.eon-netz.com/.

[4] M. Braun, G. Arnold, and H. Laukamp, "Plugging into the Zeitgeist," IEEE Power and Energy Magazine, vol. 7, no. 3, pp. 63-76, 2009.

[5] Comitato Elettrotecnico Italiano, “CEI 0-21: Reference technical rules for connecting users to the active and passive LV distribution companies of electricity," http://www.ceiweb.it/.

[6] H. Kobayashi, "Fault ride through requirements and measures of distributed PV systems in Japan," in Proceedings of the IEEEPES General Meeting, pp. 1-6, July 2012.

[7] R. Teodorescu, M. Liserre, and P. Rodriguez, Grid Converters For Photovoltaic and Wind Power Systems, Wiley-IEEE Press, 2011.

[8] F. Blaabjerg, R. Teodorescu, M. Liserre, and A. V. Timbus, "Overview of control and grid synchronization for distributed power generation systems," IEEE Transactions on Industrial Electronics, vol. 53, no. 5, pp. 1398-1409, 2006.

[9] S. B. Kjaer, J. K. Pedersen, and F. Blaabjerg, "A review of singlephase grid-connected inverters for photovoltaic modules," IEEE Transactions on Industry Applications, vol. 41, no. 5, pp. 12921306, 2005.

[10] Y. Yang, F. Blaabjerg, and Z. Zou, "Benchmarking of grid fault modes in single-phase grid-connected photovoltaic systems," in Proceedings of the IEEE Energy Conversion Congress and Exposition (ECCE '12), pp. 4370-4377, September 2012.

[11] K. Fujii, N. Kanao, T. Yamada, and Y. Okuma, "Fault ride through capability for solar inverters," in Proceedings of the European Power Electronics (EPE '11), pp. 1-9, 2011.

[12] M. Z. C. Wanik, A. Mohamed, A. F. A. Kadir, and I. Erlich, "Low voltage ride through capability of fuel cell generation system connected to low voltage network," in Proceedings of the IEEE Conference on Clean Energy and Technology (CET '11), pp. 369373, June 2011.

[13] R. A. Mastromauro, M. Liserre, T. Kerekes, and A. Dell'Aquila, "A single-phase voltage-controlled grid-connected photovoltaic system with power quality conditioner functionality," IEEE Transactions on Industrial Electronics, vol. 56, no. 11, pp. 44364444, 2009.

[14] C. H. Benz, W. T. Franke, and F. W. Fuchs, "Low voltage ride through capability of a $5 \mathrm{~kW}$ grid-tied solar inverter," in Proceedings of the 14th International Power Electronics and Motion Control Conference (EPE-PEMC '10), pp. T1213-T1220, September 2010.

[15] G. M. S. Azevedo, G. Vazquez, A. Luna, D. Aguilar, and A. Rolan, "Photovoltaic inverters with fault ride-through capability", in IEEE International Symposium on Industrial Electronics (IEEE ISIE '09), pp. 549-553, July 2009.

[16] P. Rodriguez, A. Luna, R. Munoz-Aguilar, F. Corcoles, R. Teodorescu, and F. Blaabjerg, "Control of power converters in distributed generation applications under grid fault conditions," in Proceedings of the European Conference on Cognitive Ergonomics (ECCE '11), pp. 2649-2656, September 2011.

[17] M. Saitou and T. Shimizu, "Generalized theory of instantaneous active and reactive powers in single-phase circuits based on Hilbert transform," in Proceedings of the IEEE 33rd Annual Power Electronics Specialists Conference (PESC '02), pp. 14191424, June 2002.
[18] S. Dasgupta, S. K. Sahoo, and S. K. Panda, "Single-phase inverter control techniques for interfacing renewable energy sources with microgrid-Part I: parallel-connected inverter topology with active and reactive power flow control along with grid current shaping," IEEE Transactions on Power Electronics, vol. 26, no. 3, pp. 717-731, 2011.

[19] S. A. Khajehoddin, M. K. Ghartemani, A. Bakhshai, and P. Jain, "A power control method with simple structure and fast dynamic response for single-phase grid-connected DG systems," IEEE Transactions on Power Electronics, vol. 28, no. 1, pp. 221-233, 2013.

[20] J. C. Vasquez, R. A. Mastromauro, J. M. Guerrero, and M. Liserre, "Voltage support provided by a droop-controlled multifunctional inverter," IEEE Transactions on Industrial Electronics, vol. 56, no. 11, pp. 4510-4519, 2009.

[21] D. Kai, K. W. E. Cheng, X. D. Xue et al., "A novel detection method for voltage sags," in Proceedings of the International Conference on Power Electronics Systems and Applications (ICPESA '06), pp. 250-255, November 2006.

[22] D.-M. Lee, T. G. Habetler, R. G. Harley, T. L. Keister, and J. R. Rostron, "A voltage sag supporter utilizing a PWM-switched autotransformer," IEEE Transactions on Power Electronics, vol. 22, no. 2, pp. 626-635, 2007.

[23] B. Bae, J. Lee, J. Jeong, and B. Han, "Line-interactive singlephase dynamic voltage restorer with novel sag detection algorithm," IEEE Transactions on Power Delivery, vol. 25, no. 4, pp. 2702-2709, 2010.

[24] C. Fitzer, M. Barnes, and P. Green, "Voltage sag detection technique for a dynamic voltage restorer," IEEE Transactions on Industry Applications, vol. 40, no. 1, pp. 203-212, 2004.

[25] O. C. Montero-Hernández and P. N. Enjeti, "A fast detection algorithm suitable for mitigation of numerous power quality disturbances," IEEE Transactions on Industry Applications, vol. 41, no. 6, pp. 1684-1690, 2005.

[26] S.-F. Chou, C.-T. Lee, P.-T. Cheng, and F. Blaabjerg, "A reactive current injection technique for renewable energy converters in low voltage ride-through operations," in Proceedings of the IEEE-PES General Meeting, pp. 1-7, July 2011.

[27] C.-T. Lee, C.-W. Hsu, and P.-T. Cheng, "A low-voltage ridethrough technique for grid-connected converters of distributed energy resources," IEEE Transactions on Industry Applications, vol. 47, no. 4, pp. 1821-1832, 2011.

[28] M. Ciobotaru, R. Teodorescu, and F. Blaabjerg, "Control of single-stage single-phase PV inverter," in Proceedings of the European Conference on Power Electronics and Applications (EPE '05), pp. 1-10, September 2005.

[29] D. Dong, T. Thacker, R. Burgos, F. Wang, and D. Boroyevich, "On zero steady-state error voltage control of single-phase PWM inverters with different load types," IEEE Transactions on Power Electronics, vol. 26, no. 11, pp. 3285-3297, 2011.

[30] S. Jiang, D. Cao, Y. Li, J. Liu, and F. Z. Peng, "Low-THD, fast-transient, and cost-effective synchronous-frame repetitive controller for three-phase UPS inverters," IEEE Transactions on Power Electronics, vol. 27, no. 6, pp. 2994-3005, 2012.

[31] Plexim GmbH, "PLECS 3. 3. 1 User Manual," 2012, http://www plexim.com. 

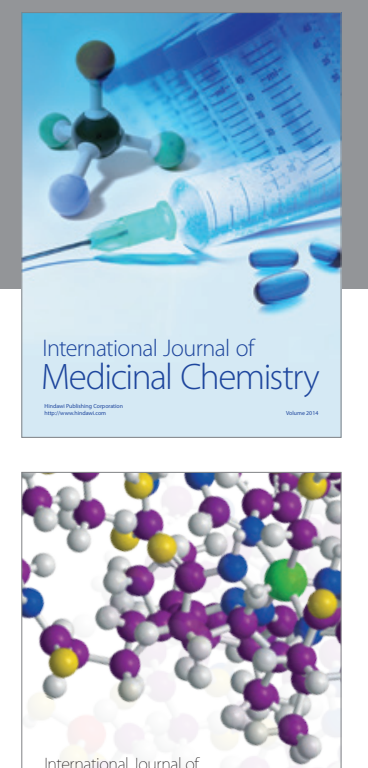

\section{Carbohydrate} Chemistry

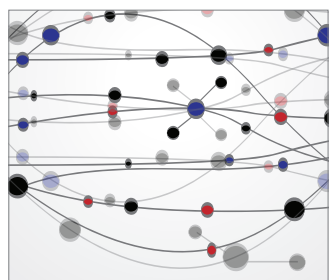

The Scientific World Journal
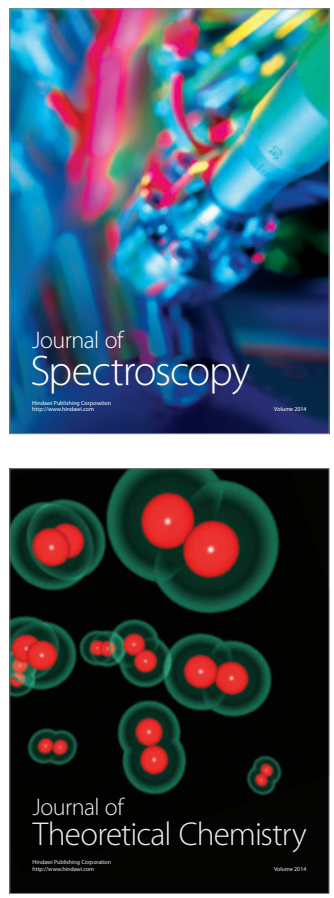
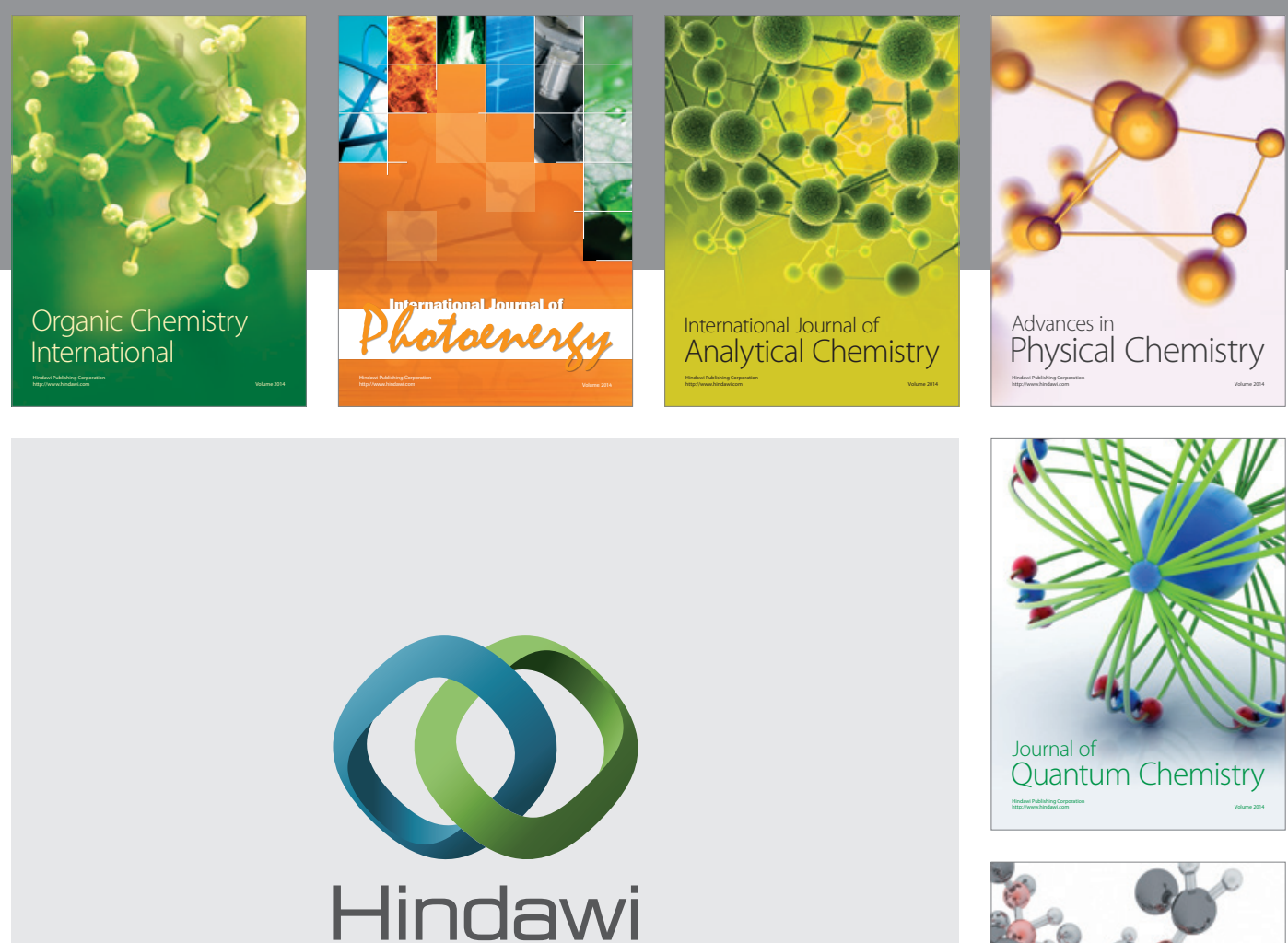

Submit your manuscripts at

http://www.hindawi.com

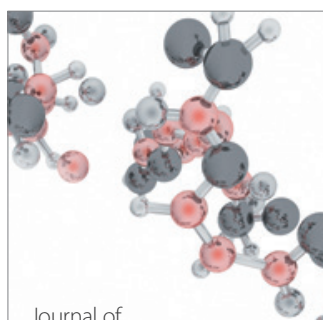

Analytical Methods

in Chemistry

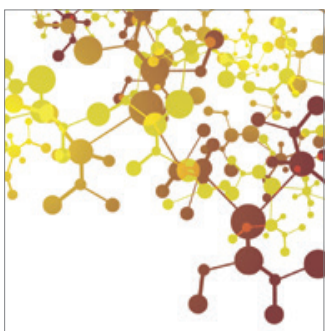

Journal of

Applied Chemistry

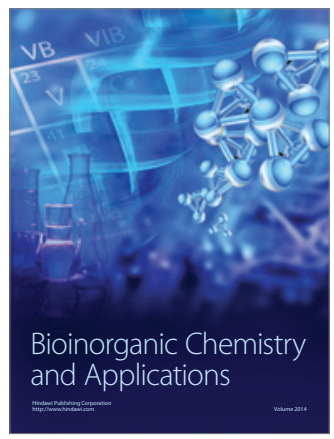

Inorganic Chemistry
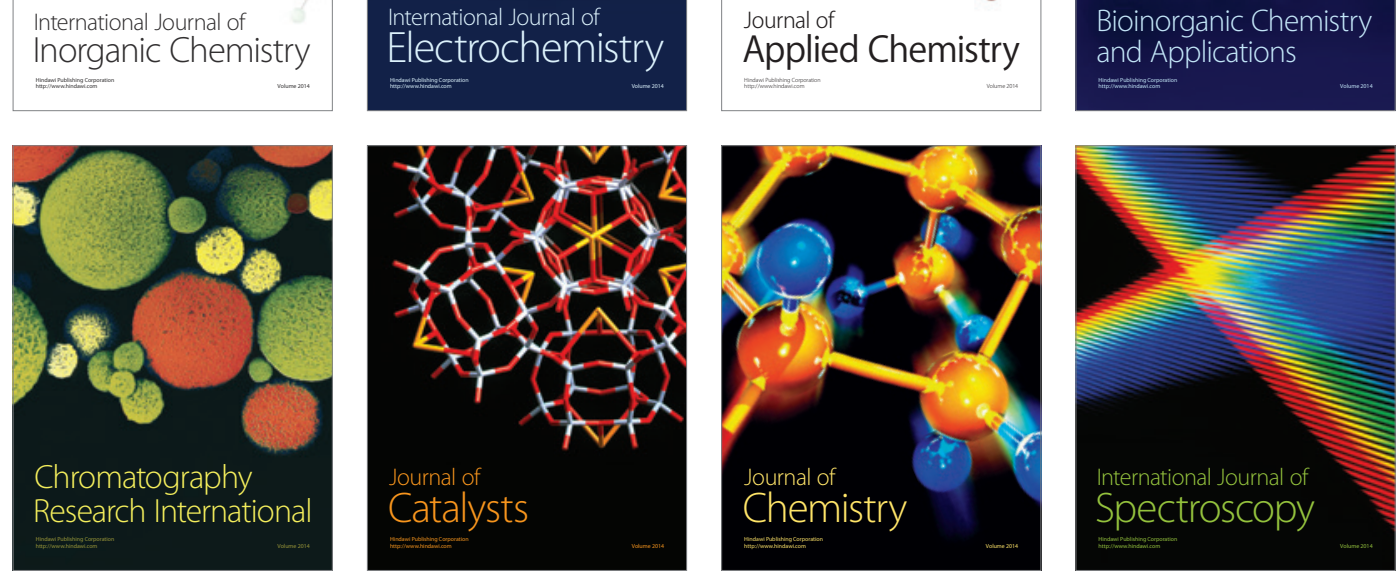